\title{
UPTAKE OF EYE CARE SERVICES IN UNIVERSITY OF CALABAR TEACHING HOSPITAL, CROSS RIVER STATE, NIGERIA

\author{
BY
}

EKPENYONG*, B. N AND IKPEME, B.M.

DEPARTMENT OF OPHTHALMOLOGY, UNIVERSITY OF CALABAR,

CROSS RIVER STATE, NIGERIA.

EMAIL: benyita2001@yahoo.com

*Corresponding author

\begin{abstract}
7 his study was carried out to determine the importance of alternative sources of eye care services in delay in seeking ophthalmic treatment in University of Calabar teaching hospital (UCTH). A total of 580 patients who visited the hospital within 3 months of the study period October 2003 to December 2003, were examined and questionnaires administered on them. In this report, there was an observed long interval between times of onset of symptoms of eye pain and time ophthalmic consultation was sought, which is an important cause of blindness. The reason for this avoidable delay has been attributed in the study to use of alternative services (50\%; Self medication/chemist, traditional medication, market eye wear sellers, prayer house/praying), ignorance (18.79\%), poverty (14.14\%) and time/distance (10.34\%). A lot of these delays if avoided would lead to reduction in the avoidable causes of blindness.
\end{abstract}

KEYWORDS: Avoidable blindness, eye care services, orthodox eye care, traditional medication, alternative eye care.

\section{INTRODUCTION}

Utilization of health care services including eye care services is influenced by a people's health seeking behavior. It is a fact that behavior or life style is a product of social or cultural condition. To this end, there are a lot of different variations in illness behavior of people of different groups and age. The behavior we exhibit is also part of our own coping mechanisms, which affects the use, delay in use and non use of orthodox healthcare.

Throughout the world, patients in unprecedented numbers are going outside of conventional medicine to look for help. This is a movement that has been building up since the late 1960s and it is now reaching the point that visits to alternative practitioners exceeds visits to primary care providers ${ }^{1}$.

In Nigeria and most other developing countries, patients tend to seek the alternative medical system first in the treatment of eye diseases before the conventional medicine. This accounts for some delay in the utilization of orthodox source of eye care services. This is an important cause of avoidable blindness, especially in cases where early detection and treatment would have prevented the victim from blindness.

As population ages in both developed and developing regions of the world, the burden of eye diseases will increase. These diseases on their own alone may not cause blindness. Some behavioral factors that influence utilization of eye care services are contributory to, and play important role in the prevention of blindness.

\section{RESEARCH METHODOLOGY}

A total of 580 new patients who visited the University of Calabar teaching hospital within the three months study period October 2003 December 2003 were interviewed through a questionnaire and screened for diagnosis. Information about age, sex, occupation, place of residence, presenting complaint, duration of complaint, reason for delay, alternative sources of eye care and others were obtained.

Data were tabulated and analyzed, using simple proportion and percentages.

\section{RESULTS}

The age and sex distribution of the 580 patients seen is as shown in table $1,333(57 \%)$ were females, while 247(43\%) were males. The data on the duration of patients complaints/symptoms of eye pains before visit to the hospital shown in table 1 indicate that only $47(8.10 \%)$ of the patients interviewed reported within one week of symptoms. Another 168 (28.97\%) reported after a period of one week to six months, while 356 (62.93\%) reported after six months and above. 
The questionnaire was also designed to find out the reasons for this delay. The result as shown in table 3 indicates that $130(22.41 \%)$ of those interviewed gave self medication and visit to patent chemist shops for treatment as the reasons for delay to visit the hospital eye clinic for examination and treatment. Those who felt ignorant of what to do and as such, did not come on time were $109(18.79 \%)$, while $82(14.14 \%)$ said they had no money to visit the hospital. Those who used traditional medication first before visit to eye clinic for examination accounted for $89(15.44 \%)$ of those interviewed. Another 55 (9.48\%) visited other eye clinic before coming and that accounted for their delay to visit the UCTH eye clinic. Those who gave lack of time due to busy schedule and distance of hospital as their reason for delay constituted $60(10.34 \%)$. Some others who were delayed because they were either praying or visited prayer house for healing accounted for $17(4.31 \%)$, while others which include market glass sellers, no reasons and superstitious beliefs accounted for 30 (5.17\%; table 3$)$.

The result in table 2 (Alternative sources of eye care in Cross River State) shows that majority of the respondents undergo self medication first as an alternative source of eye care when they have eye problem. The use of traditional medication was identified as the second important alternative source of eye care in Cross River State. One hundred and fifty seven (27.07\%) of the patients interviewed practiced this. The forms of traditional medications used include urine, sugar solution, petrol, palm wine, herbs, salt solution, breast milk, palm oil, leaves-extract (cassava leaves, scent leaves, tomatoes leaves ), lime, hot palm, saliva and kernel oil. Those that patronize market eye wear sellers for their reading eye problems were 28 $(4.82 \%)$, while those that visit the prayer houses/churches for healing as alternative sources of eye care accounted for $25(4.31 \%)$.

\section{DISCUSSION}

The study has revealed four alternative sources of eye care in Cross River State. They include selfmedication/chemist $(63.79 \%)$ traditional medication $(27.07 \%)$, prayer houses/churches $(4.31 \%)$ and market eye wear sellers $(4.82 \%)$. These four types of alternative sources of eye care also accounted for about $50 \%$ of the patients' reason for delay in the utilization of eye care services in UCTH. If this delay could be minimized then, the preventable causes of blindness can be avoided or reduced to a minimum. Blindness from glaucoma for instance can be prevented if the patients visit the hospital on time. But that has not been the case, most of the patients with glaucoma came very late to the hospital, when the vision in the eye is almost gone, which is usually irreversible. The same is applicable to corneal disease that eventually leads to blindness from corneal opacity.

Refractive error and cataract are treatable causes of blindness, yet the number of patients blind from them increases yearly. Most of the vision that is lost even after refraction is usually due to delay in utilization of orthodox source of eye care.

Other causes of delay in the utilization of eye care services in UCTH found in the study includes ignorance 109(18.79\%). The patients complained that they were ignorant of the use and availability of orthodox source of eye care, while $82(14.14 \%)$ complained of poverty/lack of money and another $60(10.34 \%)$ complained that they had to travel long distances to access eye care service. A good number $370(63.79 \%)$ of the patients use some form of self medication, buy drugs from patent drug dealers before visit to the hospital, this is not peculiar to eye care only, it is common to health care in general. The study in Zambia, found that money, distance and fear were the main barriers that prevented the blind from seeking specialist help earlier. The main reason for poor use of eye service by people with eye problem in India ${ }^{3}$, $\mathrm{Gambia}^{4}, \mathrm{Nepal}^{5}$ and South Africa ${ }^{6}$ includes fear, lack of awareness, religious and cultural beliefs, lack of transport, too old, cost in time and money, distance among others.

Traditional medication was another alternative source of eye care revealed in this study, the list of traditional eye medication used in Cross River State ranges from salt solution, sugar solution, palm wine, palm oil, palm kernel oil, cassava leaves extract, fermented cassava water, tomatoes leaves extract, breast milk, kerosene, fuel, $\mathrm{rub} / \mathrm{balm}$ among others. Most of these items are very harmful to the eye and might lead to blindness but the people were quite ignorant of these. The fact remains that these patients either see traditional healers or use traditional medication first before visiting hospitals. Couching was found to be a common traditional procedure for the treatment of blinding cataract in northern Nigeria ${ }^{7}$. 
Reasons usually include easy access, inaccessibility of orthodox eye care, low cost, simple technique, belief regarding cause of disease. There has been inadequate research on the effectiveness of plants used in the treatment of eye diseases. Most of these plants do more harm than good to the eyes. Studies have shown that $25 \%$ of corneal opacity in Tanzania and $20 \%$ childhood blindness in Nigeria and Malawi were associated with the use of traditional eye medicine ${ }^{1}$.

The study has also shown that $25(4.31 \%)$ of the patients stay at home and pray for healing to occur while some go to the prayer house for healing. It was discovered that $28(4.82 \%)$ go to market eye wear sellers for their eye problem, especially those who cannot read tiny points. They end up doing more harm than good by this approach. Three assumptions have been proposed by $\mathrm{Pal}^{7}$ to explain the use of alternative medicine: dissatisfaction, need for personal control and philosophical consequences.

By making eye care services available, accessible, affordable and acceptable to the people, a lot of the basic problems would be solved, such as difficulty in obtaining expert attention, traveling long distances which is often expensive to get appropriate treatment, failure to make use of available services and patronage of traditional and often use of dangerous eye medication can at least be alleviated.

\section{RE F E R E N C E S}

1. Pal, S. K. (2002): Complementary and alternative medicine: an overview, Current Sci, 82 (5): 518-24.

2. Lan, Y. and Boateng, W. (2002): An outreach eye care program in Zambia. J. Comm. Eye Hlth, 15 (41):13-4.

3. Fletcher, A. E., Donoghue, M., Devavaram, J., Thulasiraj, R. D., Scott, S., Abdalla, M., Shanmugham, C. A. K. and Bala-Murugan, P. (1999): Low Uptake of Eye Services in Rural India: A Challenge for Programs of Blindness Prevention. Arch. Ophthalmol: 117: 1393-9.

4. Johnson, J. G., Goode, V. and Faal, H. (1998):
Barriers to the Uptake of Cataract Surgery. Trop. Doc, 28(4): 218-20.

5. Martine, D. (1999): People who don't use eye services: "making the invisible visible". J. Comm. Eye Hlth, 12 (31): 36-8

6. Aditi, S. (2005): Barriers to the uptake of cataract surgery for women in Urban Cape Town. J. Comm. Eye Hlth, 18 (53): 80-5.

7. Mary, G. and Margreet, H. (1997): Couching and cataract extraction-A clinic based study in Northern Nigeria. J. Comm. Eye Hlth. 10 (12): 6-7. 


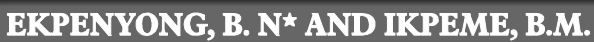

TABLE 1: DURATION OF PATIENT'S COMPLAINTS/SYMPTOMS BEFORE FIRST VISIT.

\begin{tabular}{|l|l|l|}
\hline Duration & No & \% \\
\hline With 1 week & 47 & $8.10 \%$ \\
>1 week-6months & 168 & $28.97 \%$ \\
Above 6months & 365 & $62.93 \%$ \\
\hline
\end{tabular}

TABLE 2: ALTERNATIVE SOURCES OF EYE CARE SERVICES IN CROSS RIVER STATE

\begin{tabular}{|l|l|l|}
\hline Alternative source & No & \% \\
\hline Self medication/chemist & 370 & 63.79 \\
Traditional medication & 157 & 27.07 \\
Market eye wear sellers & 28 & 4.82 \\
Prayer house/church & 25 & 4.31 \\
\hline
\end{tabular}

TABLE 3: REASONS FOR PATIENTS DELAY IN UTILIZATION OF EYE CARE SERVICES IN UCTH

\begin{tabular}{|l|l|l|}
\hline Reasons & No. & \% \\
\hline Traditional Medication & 89 & 15.44 \\
Self Medication/Chemist & 130 & 22.41 \\
Been to other Clinic & 55 & 9.48 \\
Been to Church/praying & 25 & 4.31 \\
Ignorance & 109 & 18.79 \\
Poverty & 82 & 14.14 \\
Time/Distance & 60 & 10.34 \\
Others. & 30 & 5.17 \\
\hline Total & 580 & 100 \\
\hline
\end{tabular}

